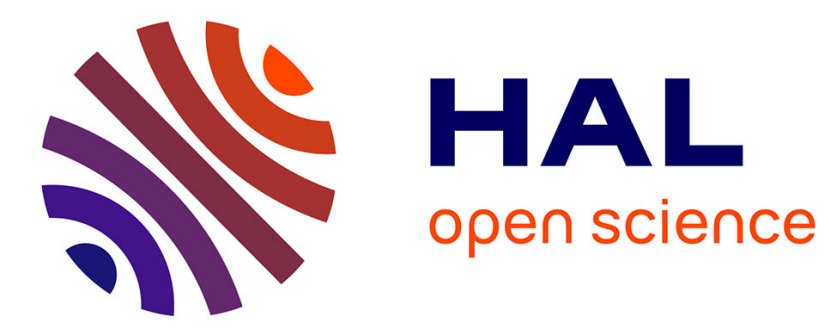

\title{
Selective Wet Etching of Silicon Germanium in Composite Vertical Nanowires
}

Zhaslan Baraissov, Antoine Pacco, Siddardha Koneti, Geeta Bisht, Federico Panciera, Frank Holsteyns, Utkur Mirsaidov

\section{> To cite this version:}

Zhaslan Baraissov, Antoine Pacco, Siddardha Koneti, Geeta Bisht, Federico Panciera, et al.. Selective Wet Etching of Silicon Germanium in Composite Vertical Nanowires. ACS Applied Materials \& Interfaces, 2019, 11 (40), pp.36839-36846. 10.1021/acsami.9b11934 . hal-02404924

\section{HAL Id: hal-02404924 https://hal.science/hal-02404924}

Submitted on 11 Dec 2019

HAL is a multi-disciplinary open access archive for the deposit and dissemination of scientific research documents, whether they are published or not. The documents may come from teaching and research institutions in France or abroad, or from public or private research centers.
L'archive ouverte pluridisciplinaire HAL, est destinée au dépôt et à la diffusion de documents scientifiques de niveau recherche, publiés ou non, émanant des établissements d'enseignement et de recherche français ou étrangers, des laboratoires publics ou privés. 


\section{Selective Wet Etching of Silicon Germanium in Composite Vertical Nanowires}

Zhaslan Baraissov ${ }^{1,2}$, Antoine Pacco ${ }^{3}$, Siddardha Koneti ${ }^{1,2}$, Geeta Bisht ${ }^{1,2}$, Federico Panciera ${ }^{1,2}$, Frank Holsteyns ${ }^{3}$, and Utkur Mirsaidov ${ }^{1,2,4,5 *}$

1. Department of Physics, National University of Singapore, Singapore 117551, Singapore

2. Centre for BioImaging Sciences, Department of Biological Sciences, National University of Singapore, Singapore 117557, Singapore

3. imec, Kapeldreef 75, B-3001, Belgium

4. Centre for Advanced 2D Materials and Graphene Research Centre, National University of Singapore, Singapore 117546, Singapore

5. Department of Materials Science and Engineering, National University of Singapore, Singapore 117575, Singapore

*Correspondence: mirsaidov@nus.edu.sg

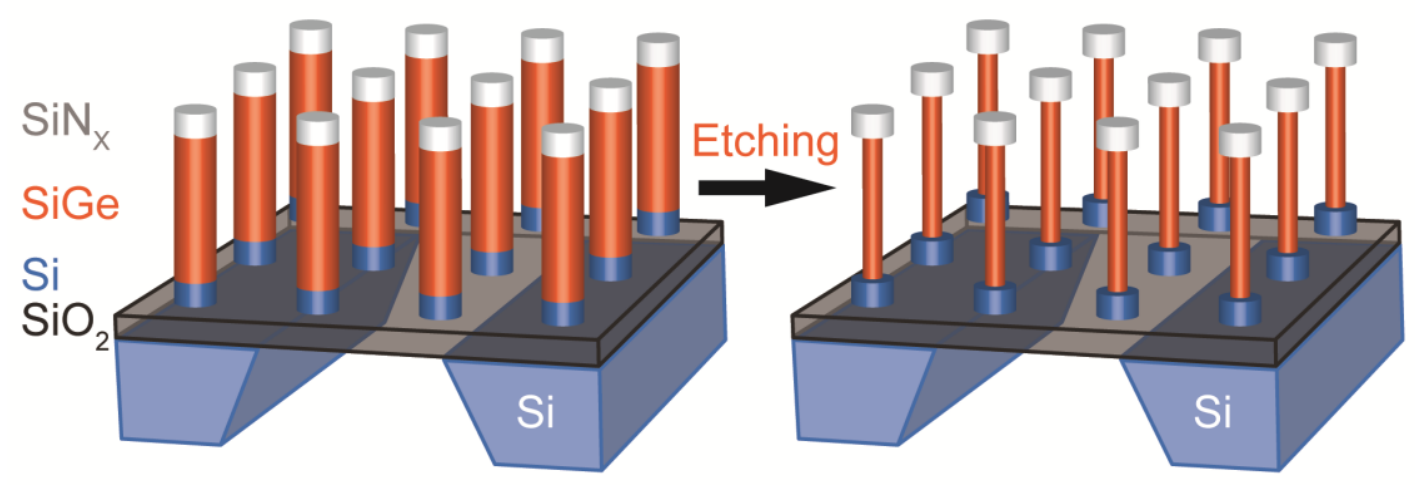

ABSTRACT: Silicon Germanium ( $\mathrm{Si}_{\mathrm{x}} \mathrm{Ge}_{1-\mathrm{x}}$ or $\mathrm{SiGe}$ ) is an important semiconductor material for the fabrication of nanowire-based gate-all-around transistors in the next-generation logic and memory devices. During the fabrication process, SiGe can either be used as a sacrificial layer to form suspended horizontal Si nanowires or, because of its higher carrier mobility, SiGe can also be used as a possible channel material that replaces $\mathrm{Si}$ in both horizontal and vertical nanowires. In both cases, there is a pressing need to understand and develop nanoscale etching processes that enable controlled and selective removal of SiGe with respect to $\mathrm{Si}$. Here, we developed and tested solution-based selective etching processes for $\mathrm{SiGe}$ in composite $\left(\mathrm{SiN}_{\mathrm{x}} / \mathrm{Si}_{0.75} \mathrm{Ge} 0.25 / \mathrm{Si}\right)$ vertical nanowires. The etching solutions were formed by 
mixing acetic acid $\left(\mathrm{CH}_{3} \mathrm{COOH}\right)$, hydrogen peroxide $\left(\mathrm{H}_{2} \mathrm{O}_{2}\right)$, and hydrofluoric acid (HF). Here, the two chemicals $\left(\mathrm{H}_{2} \mathrm{O}_{2}\right.$ and $\left.\mathrm{CH}_{3} \mathrm{COOH}\right)$ react to form highly oxidizing peracetic acid (PAA or $\mathrm{CH}_{3} \mathrm{CO}_{3} \mathrm{H}$ ). The hydrofluoric acid serves both as a catalyst for PAA formation and as an etchant for oxidized SiGe. Our study shows that an increase in either of the oxidizer concentrations increases the etch rate, and the fastest etch rate of $\mathrm{SiGe}$ is associated with the highest PAA concentration. Moreover, using in situ liquid phase TEM imaging, we tested the stability of nanowires during wet etching and identified that $\mathrm{SiGe/Si}$ interface to be the weakest plane; we found that once the diameter of the 160 -nm-tall Sio.75Ge0.25 nanowire reaches $\sim 15 \mathrm{~nm}$ during the etching, the nanowire breaks at or very close to this interface. Our study provides an important insight into the details of the wet etching of SiGe and some of the associated failure modes that are becoming extremely relevant for the fabrication processes as the size of the transistors shrink with every new device-generation.

KEYWORDS: chemical etching, silicon germanium, nanowire, nanofabrication, in situ TEM.

\section{Introduction}

The continued demand for power-efficient and high-performance microelectronics components is the key driver for miniaturization of transistors and an increase in their density on a chip. ${ }^{1}$ The performance of these nanoscale transistors depends on their architecture and materials properties. ${ }^{2}$ For example, for sub-5-nm node technology, the gate-all-around field-effect transistors (GAAFET) are expected to replace the current FinFET architectures because of better electrostatic performance. ${ }^{3}$ GAAFETs can be both vertical and lateral. ${ }^{4}$ Vertical GAAFETs are very challenging to integrate into current CMOS fabrication process flows, but this architecture can potentially enable the fabrication of transistors at very high densities needed to keep up with the scaling trend set by Moore's law. ${ }^{5}$ Lateral GAAFETs, on the other hand, can be achieved by using the current process flows. ${ }^{3}$ The fabrication of lateral GAAFETs employs SiGe/Si heterostructures, where strain induced by sacrificial SiGe layer, increases the carrier mobility of Si nanowires, ${ }^{6-7}$ thus improving the overall device performance. ${ }^{8-11}$ At present, $\mathrm{Si}$ is still the best choice for a channel material compared to other semiconductors with higher mobility such as Ge and III-V materials. The reason for this is because, for very narrow Ge and III-V nanowires, there is a significant loss in their carrier mobility causing them to lose advantage over the $\mathrm{Si}^{12-14}$ For vertical GAAFETs, this issue of mobility loss can be offset since the gate length is defined in a vertical direction, which allows opting for longer gate lengths, thus relaxing the requirement on nanowire diameter, making it feasible to take the advantage of materials with higher mobility. ${ }^{12}$

Fabrication of both vertical and lateral nanowires requires precise control over SiGe etching. In the case of lateral GAAFETs, where SiGe is used as a sacrificial layer, ${ }^{3}$ the $\mathrm{SiGe}$ has to be fully removed while preserving the $\mathrm{Si}$. For vertical GAAFETs, precisely controlled etching of $\mathrm{SiGe}$ is essential to minimize the variation in device dimensions because the etching defines the size uniformity and the surface roughness of the nanowires. ${ }^{15}$ Traditionally, dry plasma etching has been the most common way to remove the material when forming vertical nanostructures. 
However, dry etching processes have several drawbacks. First, during dry plasma etching, the damage caused by ions can penetrate up to 20-nm-deep into the semiconductor surface that is being etched. ${ }^{16-17}$ Second, dry plasma etching results in non-uniform etching across the wafer. ${ }^{18}$ Third, the etch rate is aspect ratio dependent. ${ }^{19}$ Fourth, the etch selectivity for SiGe with respect to $\mathrm{Si}$ is generally low. ${ }^{20-22}$ Combining dry etching methods with wet chemical etching can potentially overcome all these issues. ${ }^{23}$ For example, during the solution based wet etching, etchant molecules react only with the surface atoms, and therefore, do not damage the underlying material. ${ }^{23}$ Moreover, wet etching can be tuned to have high selectivity for different materials. ${ }^{23}$ Hence developing well-controlled isotropic etching processes for SiGe that have high selectivity with respect to $\mathrm{Si}$ is essential for the reliable fabrication of next-generation transistors. Here, the aim of our study is to explore selective wet chemical etching of SiGe towards $\mathrm{Si}$ using $\mathrm{SiN}_{\mathrm{x}} / \mathrm{SiGe} / \mathrm{Si}$ test nanostructures and provide a detailed insight that can be used for the development of a broad range of nanofabrication processes.

\section{Results and Discussion}

Common solutions for selective etching of crystalline $\mathrm{SiGe}$ (c-SiGe) with respect to c-Si are $\mathrm{HNO}_{3}: \mathrm{HF}: \mathrm{H}_{2} \mathrm{O}$ (ref. ${ }^{24-26}$ ) and $\mathrm{H}_{2} \mathrm{O}_{2}: \mathrm{HF}: \mathrm{H}_{2} \mathrm{O} .{ }^{27-28}$ The etch selectivity of these solutions stems from faster oxidation of the $\mathrm{Ge}$ compared to the $\mathrm{Si}$ in the presence of strong $\mathrm{HNO}_{3}$ and $\mathrm{H}_{2} \mathrm{O}_{2}$ oxidizers. ${ }^{24-}$

${ }^{26}$ Furthermore, the substitution of water in the $\mathrm{H}_{2} \mathrm{O}_{2}: \mathrm{HF}: \mathrm{H}_{2} \mathrm{O}$ mixture as the diluent by acetic acid $\left(\mathrm{CH}_{3} \mathrm{COOH}\right)$ increases the etch rate, selectivity, and etch uniformity of SiGe ${ }^{29}$ In these peroxideacid-based mixtures, ${ }^{30}$ the high reactivity of the solution with $\mathrm{SiGe}$ is due to the acid-catalyzed formation of another oxidizing agent: peracetic acid (PAA or $\mathrm{CH}_{3} \mathrm{CO}_{3} \mathrm{H}$ ) ${ }^{31}$ Here, PAA is a product of the reaction between acetic acid and hydrogen peroxide:

$$
\mathrm{CH}_{3} \mathrm{COOH}+\mathrm{H}_{2} \mathrm{O}_{2} \rightleftarrows \mathrm{CH}_{3} \mathrm{CO}_{3} \mathrm{H}+\mathrm{H}_{2} \mathrm{O}
$$

This reaction is catalyzed by strong acids such as $\mathrm{HF}$ or $\mathrm{H}_{2} \mathrm{SO}_{4} \cdot{ }^{32}$ In the case of SiGe, $\mathrm{HF}$ also etches $\mathrm{Si}$ and Ge oxides. ${ }^{33-34}$ Despite being the most common etchant for SiGe, very little is known about the details of the etch chemistry of $\mathrm{HF}: \mathrm{H}_{2} \mathrm{O}_{2}: \mathrm{CH}_{3} \mathrm{COOH}: \mathrm{H}_{2} \mathrm{O}$ and the etchant parameters that determine the etch rates. ${ }^{21,29,35-39}$ Moreover, earlier studies of etch chemistries for SiGe and Si focused on bulk structures ${ }^{21,29,35-36,38-39}$ and the details of etching for sub-100-nm SiGe nanostructures, which is essential for transistor fabrication, are largely unexplored. Moreover, the presence of two oxidizing agents $\left(\mathrm{H}_{2} \mathrm{O}_{2}\right.$ and PAA) in these solutions further complicates the identification of the underlying etch mechanisms, and it is unclear how the two oxidizing agents will work in tandem during the etching. The early study by Carns et al. ${ }^{36}$ showed that the etch rate of SiGe depends on the constituents of an etching solution and their concentrations, Ge content, dopant type, temperature, and stirring conditions. However, the results of SiGe etching using various initial mix ratios are difficult to compare because final equilibrium concentrations of constituents in the solution differ from the initial concentrations before the mixing. Hence, the 
relation between the oxidation and dissolution processes in these mixtures is not properly established, and the parameter space (i.e., the etch rates at different equilibrium concentrations of the chemicals in an etching solution) has not been thoroughly explored.

The final equilibrium concentrations of all the etchant constituents after the reaction can be obtained from the equilibrium constants established in earlier studies on the formation kinetics of PAA. ${ }^{31,40-42}$ According to a study by Dulneva et al.,$^{41}$ the chemical equilibrium constant $\left(K_{\text {eq }}\right)$ of the reaction should remain constant across the different catalyst concentrations $\left(K_{\mathrm{eq}}=2.10\right.$ at $T=$ $\left.20{ }^{\circ} \mathrm{C}\right)$. Later, in more comprehensive studies, Zhao et al. ${ }^{31}$ and Jankovic et al ${ }^{42}$ came up with empirical formulas for $K_{\text {eq }}(T)$ from which we estimate $K_{\text {eq }}$ at $T=25^{\circ} \mathrm{C}$ to be $\sim 2.84$.
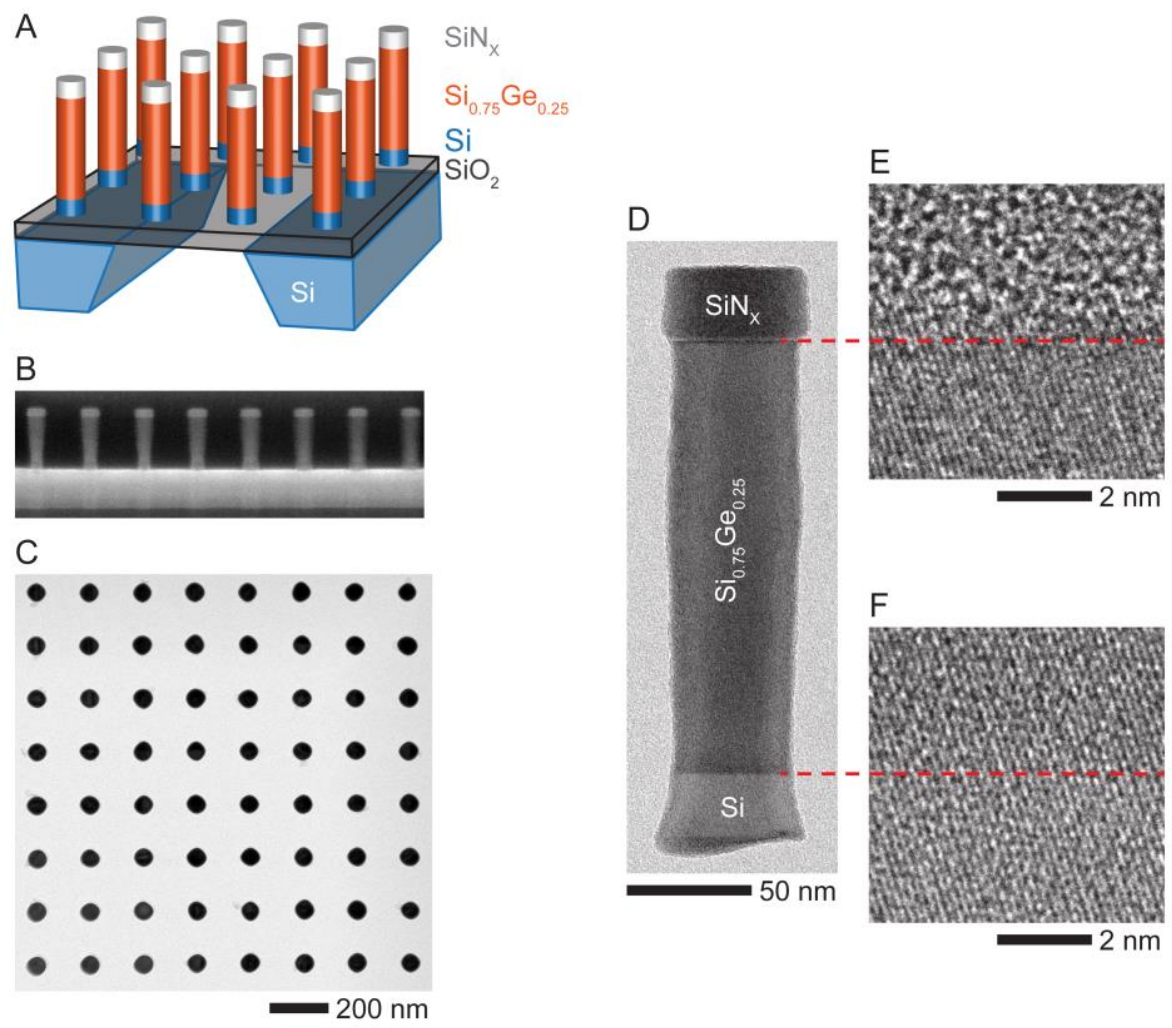

Figure 1. Overview of Sio.75Ge0.25 (SiGe) composite nanowires. (A) Schematic of the test chip used for TEM imaging of the etched nanowires. (B) Side-view SEM image showing the array of composite $\mathrm{SiN}_{\mathrm{x}} / \mathrm{SiGe} / \mathrm{Si}$ nanowires on a $\mathrm{SiO}_{2}$ film. (C) Top-down TEM image of an $8 \times 8$ array of the composite nanowires. (D) TEM image of the isolated nanowire, and the corresponding high-resolution images of $(\mathbf{E}) \mathrm{a}_{-} \mathrm{SiN}_{\mathrm{x}} / \mathrm{c}-\mathrm{SiGe}$ and $(\mathbf{F}) \mathrm{c}-\mathrm{SiGe} / \mathrm{c}-\mathrm{Si}$ (lower panel) interfaces. Note that there are no visible defects at c-SiGe/c-Si interface.

Here, we study the wet chemical etching of 50-nm-diameter SiGe nanowires, by fabricating arrays of composite nanowire on 145-nm-thick $\mathrm{SiO}_{2}$ membranes as shown in (Figure 1A-C) (see Experimental Section for fabrication details). The composite nanowires consist of three vertically 
stacked layers of 30-nm-tall c-Si at the base, $160-\mathrm{nm}$-tall c-Si ${ }_{0.75} \mathrm{Ge}_{0.25}$ in the middle, and 30-nmtall amorphous $\mathrm{SiN}_{\mathrm{x}}\left(\mathrm{a}-\mathrm{SiN}_{\mathrm{x}}\right)$ hard mask at the top (for simplicity, we will refer to them as $\mathrm{Si}, \mathrm{SiGe}$, and $\mathrm{SiN}_{\mathrm{x}}$, respectively) (Figure $1 \mathrm{D}-\mathrm{F}$ ). To study the etching of $\mathrm{SiGe}$, we use etching solutions comprising different volume ratios of $\mathrm{HF}: \mathrm{H}_{2} \mathrm{O}_{2}: \mathrm{CH}_{3} \mathrm{COOH}: \mathrm{H}_{2} \mathrm{O}$, and we calculate the final equilibrium concentrations of the constituents using the chemical equilibrium reaction constant obtained by Jankovic et al. ${ }^{42}$ (Supporting Information Section 1). We chose the HF concentrations to be $<1 \%(\mathrm{v} / \mathrm{v})$ because, at high HF concentrations, the solution is aggressive towards $\mathrm{SiO}_{2}$ and $\mathrm{Si}$ (i.e., might form pits on strained $\mathrm{Si}$ surface ${ }^{37}$ and starts to etch the $\mathrm{SiO}_{2}$ ). These drawbacks make PAA solutions with high HF concentration undesirable for nanoscale etching in industrial fabrication, where precise etch control, and uniform and damage-free surfaces are required.

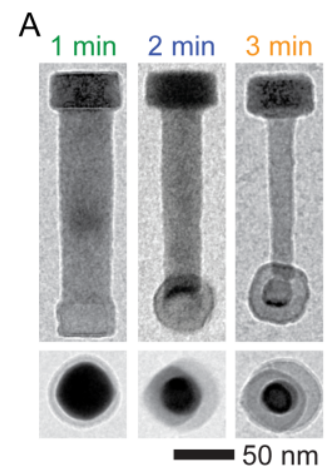

$\mathrm{D}$

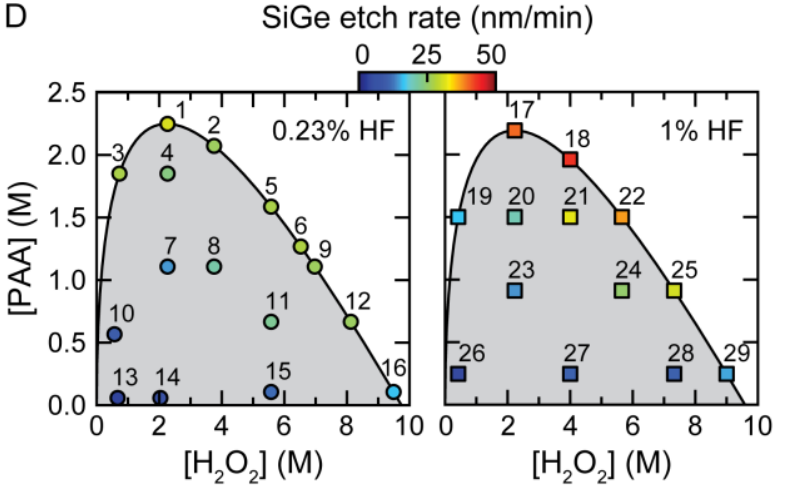

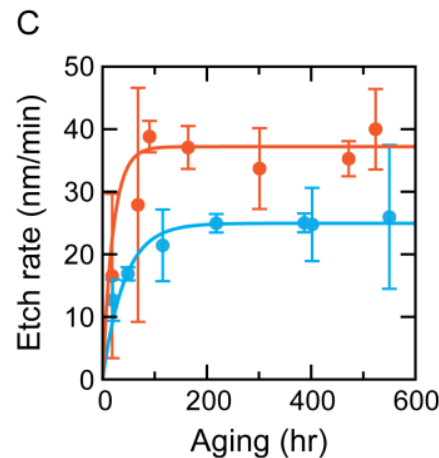

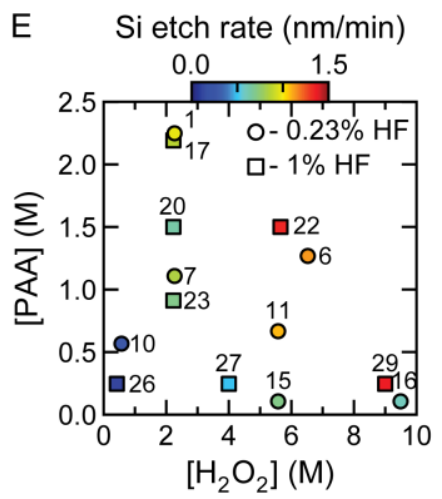

Figure 2. Etching of SiGe with a peracetic $\left(\mathrm{CH}_{3} \mathrm{CO}_{3} \mathrm{H}\right)$ solution. (A) Side-view TEM images of the nanowires on a $\mathrm{SiO}_{2}$ membrane (upper panels) and top-down view of the erect nanowires (lower panels) after etching with the solution-10 ( $\left.\mathrm{HF}: \mathrm{H}_{2} \mathrm{O}_{2}: \mathrm{CH}_{3} \mathrm{COOH}: \mathrm{H}_{2} \mathrm{O}=1: 23.9: 108.7: 72.4\right)$ for 1, 2, and $3 \mathrm{~min}$. Note that these are volume ratios of the undiluted stock solutions (Experimental Section) used for preparing the etching solution. (B) Left: Distribution of the diameters of the SiGe fragment of the composite nanowires at different etching times. Each distribution has been fitted with a Gaussian function (black line). Right: The average nanowire diameter versus etching time. The error bar corresponds to a mean half-width of the Gaussian fits shown in the left panel. (C) Etch rates for solution-1 (HF: $\left.\mathrm{H}_{2} \mathrm{O}_{2}: \mathrm{CH}_{3} \mathrm{COOH}: \mathrm{H}_{2} \mathrm{O}=1: 95: 110: 0\right)$ (blue circles) and solution-17 ( $\mathrm{HF}: \mathrm{H}_{2} \mathrm{O}_{2}: \mathrm{CH}_{3} \mathrm{COOH}: \mathrm{H}_{2} \mathrm{O}=5: 47.1: 187.9: 0$ ) (orange circles) as a function of their aging times. The blue and orange curves represent the respective fits to an exponential plateau function: Etch rate $=A(1-\exp (-t / \tau))$. From the fits, we find that the etch rates for solution1 and solution-17 stabilize after the characteristic aging time $(\tau)$ of 190 hours and 90 hours, respectively. (D) Etch rates of $\mathrm{SiGe}$ as a function of the calculated PAA and $\mathrm{H}_{2} \mathrm{O}_{2}$ equilibrium concentrations for fixed $0.27 \%$ (w/v) (left) 
and $1.15 \%(\mathrm{w} / \mathrm{v})($ right $) \mathrm{HF}$ concentrations. The area under the black curve identifies all achievable dilutions of etching solutions. (E) Etch rate of $\mathrm{Si}$ as a function of PAA and $\mathrm{H}_{2} \mathrm{O}_{2}$ concentration at $0.22 \%$ (v/v) (circle) and $0.93 \%$ (v/v) (square) HF. The details about the solutions numbered in the panels (D-E) are given in Supporting Information Section 1 .

We explored the wet etching characteristics of sixteen solutions with $0.27 \%(\mathrm{w} / \mathrm{v}) \mathrm{HF}$ and thirteen solutions with $1.15 \%(\mathrm{w} / \mathrm{v}) \mathrm{HF}$ concentrations containing different equilibrium concentrations of $\mathrm{H}_{2} \mathrm{O}_{2}, \mathrm{CH}_{3} \mathrm{COOH}$, and PAA (see Supporting Information Section 1 for details of the solutions). The SiGe etch rates in the solutions were measured by quenching the etching reaction of nanowires at three to four different time-points and by imaging them with TEM to measure their diameters as a function of the etch time (Figure 2A-B) (Supporting Information Section 2 describes the methods for extracting the etch rates). The etchant selectively removes $\mathrm{SiGe}$ as seen by a negligible change in the diameter of the $\mathrm{Si}$ bases (Figure 2A). To ensure the robustness of the etch rate measurements of $\mathrm{SiGe}$, we measured the diameter of more than hundred nanowires for each time point of each etch solution. Figure $2 \mathrm{~B}$ shows the distribution of nanowire diameters before the etching and after 1, 2, and 3 min of etching with the solution-10 $\left(\mathrm{HF}_{2} \mathrm{H}_{2} \mathrm{O}_{2}: \mathrm{CH}_{3} \mathrm{COOH}: \mathrm{H}_{2} \mathrm{O}=\right.$ $1: 23.9: 108.7: 72.4$, Note that the ratios of the constituents of the etchant are the volume ratio of their undiluted stock solutions given in the Experimental Section). For this solution, a linear fit to the average diameters versus time gives an etch rate of $5.0 \pm 0.7 \mathrm{~nm} / \mathrm{min}$. It should be noted that the formation of PAA is not an instant reaction, and the solution equilibrates with aging. We investigated the effect of aging on the etch rates of $\mathrm{SiGe}$ in the solution-1 $\left(\mathrm{HF}: \mathrm{H}_{2} \mathrm{O}_{2}: \mathrm{CH}_{3} \mathrm{COOH}: \mathrm{H}_{2} \mathrm{O}=1: 95: 110: 0\right)$ and solution-17 (HF: $\mathrm{H}_{2} \mathrm{O}_{2}: \mathrm{CH}_{3} \mathrm{COOH}: \mathrm{H}_{2} \mathrm{O}=$ 5:47.1:187.9:0), which have the highest PAA concentration for a given HF concentration of $0.27 \%$ $(\mathrm{w} / \mathrm{v})$ and $1.15 \%(\mathrm{w} / \mathrm{v})$ (Figure 2C), respectively. We found the aging times needed for the etch rates to plateau to a stable value to be $\sim 190$ hours (solution-1) and $\sim 90$ hours (solution-17). These aging times needed for the reactants and products to equilibrate at $<1 \%(\mathrm{v} / \mathrm{v}) \mathrm{HF}$ concentrations are consistent with the earlier studies at much higher HF concentrations. ${ }^{36}$ Figure $2 \mathrm{D}$ summarizes our etch rate measurements derived from analyzing 9530 nanowires for the solutions at different equilibrium concentrations of the etchant constituents. Here, the etching solutions with HF concentrations of $0.27 \%(\mathrm{w} / \mathrm{v})$ and $1.15 \%(\mathrm{w} / \mathrm{v})$ were aged for $>360$ hours and $>110$ hours, respectively (Supporting Information Section 1). Black curves in Figure 2D represent the solutions that form from undiluted stock solutions of $\mathrm{HF}, \mathrm{H}_{2} \mathrm{O}_{2}$, and $\mathrm{CH}_{3} \mathrm{COOH}$ (i.e., when no $\mathrm{H}_{2} \mathrm{O}$ is added) (Supporting Information Section 3). The solutions under the curve (i.e., gray regions in Figure 2D) are obtained for the etchants diluted with $\mathrm{H}_{2} \mathrm{O}$ (see Supporting Information Section 1 for the details of solutions).

Our analysis in Figure 2D reveals that for fixed $\mathrm{HF}$ and $\mathrm{H}_{2} \mathrm{O}_{2}$ concentrations, the SiGe etch rate increases with increasing PAA concentration. Likewise, for fixed HF and PAA concentrations, the etch rate increases with increasing $\mathrm{H}_{2} \mathrm{O}_{2}$ concentration. For $0.27 \%$ (w/v) $\mathrm{HF}$, we found that the 
solutions 2, 5, 6, 9, and 12 on the black curve (Figure 2D: left) have similar etch rates, although the etch rates for similar PAA and $\mathrm{H}_{2} \mathrm{O}_{2}$ concentrations on the curve for $1.15 \%$ (w/v) HF increase with PAA concentration (Figure 2D: right). This comparison suggests that at $0.27 \%(\mathrm{w} / \mathrm{v}) \mathrm{HF}$ concentration, the etch rates are not limited by the oxidation rate but by the dissolution rate of the oxidized SiGe. Furthermore, from Figure 2D, we also conclude that the etch rate is more sensitive to PAA concentration than to the concentration of $\mathrm{H}_{2} \mathrm{O}_{2}$. For the solutions with $1.15 \%$ (w/v) HF, there is enough etchant in the solution, so unlike $0.27 \%$ (w/v) HF solutions, the etch kinetics is not dissolution limited. For example, a 2.4-fold increase in the PAA concentration from the solution23 to the solution-17 caused a 2.9-fold increase in the etch rate of SiGe (Figure 2D: right). On the other hand, a 3.3-fold increase in $\mathrm{H}_{2} \mathrm{O}_{2}$ concentration from solution-23 to solution-25 resulted in $2.2 \times$ higher etch rate. Furthermore, we found that the etch rates for both HF concentrations peak at the same PAA concentration of $\sim 2.2 \mathrm{M}$.

Next, to test the etch selectivity of $\mathrm{SiGe}$ against $\mathrm{Si}$, we also measured the etch rates for $\mathrm{Si}$ nanowires (Supporting Information Section 2) for the solutions with both HF concentrations ( 0.27 and $1.15 \%$ $(w / v))$. Figure $2 \mathrm{E}$ displays the low etch rates for $\mathrm{Si}$ in the solutions with different etchant and oxidizer concentrations. Similar to $\mathrm{SiGe}$, the etch rate increases with increasing PAA and $\mathrm{H}_{2} \mathrm{O}_{2}$ concentrations. However, it is important to note that unlike SiGe etching, where the etch rate depends strongly on the PAA concentration, for $\mathrm{Si}$ etching, the effect of both PAA and $\mathrm{H}_{2} \mathrm{O}_{2}$ on the etch rate is virtually identical. The maximum $\mathrm{Si}$ etch rate is achieved for the solution-22 ( $\mathrm{HF}: \mathrm{H}_{2} \mathrm{O}_{2}: \mathrm{CH}_{3} \mathrm{COOH}: \mathrm{H}_{2} \mathrm{O}=1: 160: 40: 0$ ), where the both oxidizers have relatively high concentrations $\left(\left[\mathrm{H}_{2} \mathrm{O}_{2}\right]=5.65 \mathrm{M},[\mathrm{PAA}]=1.5 \mathrm{M}\right)$. Moreover, changing the $\mathrm{HF}$ concentration does not significantly alter the $\mathrm{Si}$ etch rate. For example, the two solutions located at the PAA concentration peaks, solution-1 ( $\left.\mathrm{HF}_{2} \mathrm{H}_{2} \mathrm{O}_{2}: \mathrm{CH}_{3} \mathrm{COOH}: \mathrm{H}_{2} \mathrm{O}=1: 95: 110: 0\right)$ and solution-17 (HF: $\mathrm{H}_{2} \mathrm{O}_{2}: \mathrm{CH}_{3} \mathrm{COOH}: \mathrm{H}_{2} \mathrm{O}=5: 47.1: 187.9: 0$ ), have similar $\mathrm{Si}$ etch rates despite a more than the 4fold increase in the HF concentration of the latter solution. Here, the etch selectivities for SiGe over $\mathrm{Si}$ are $\sim 30: 1$ for the solution-1 (HF: $\mathrm{H}_{2} \mathrm{O}_{2}: \mathrm{CH}_{3} \mathrm{COOH}: \mathrm{H}_{2} \mathrm{O}=1: 95: 110: 0$ ) and $\sim 50: 1$ for the solution-17 (HF: $\left.\mathrm{H}_{2} \mathrm{O}_{2}: \mathrm{CH}_{3} \mathrm{COOH}: \mathrm{H}_{2} \mathrm{O}=5: 47.1: 187.9: 0\right)$. These observations imply that the etch rate of $\mathrm{Si}$ is oxidation-limited. 

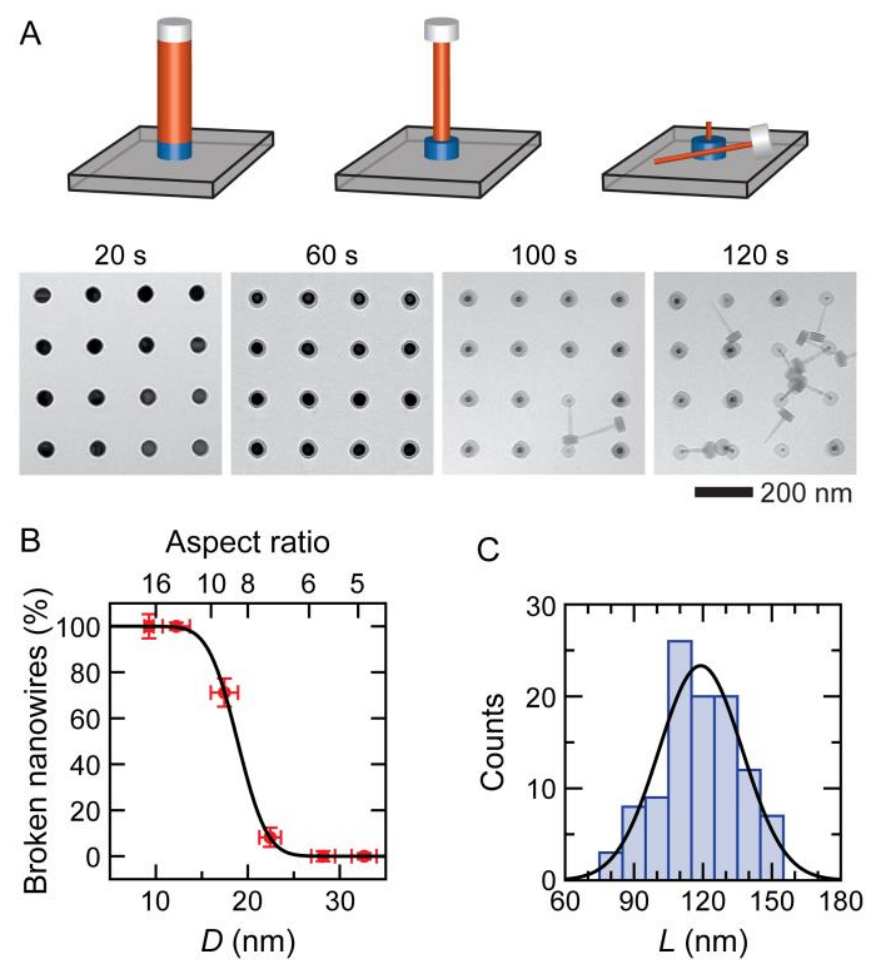

Figure 3. Breaking of vertical composite nanostructures during drying. (A) Schematic illustration and top-down TEM images of nanowire arrays after etching with solution-7 ( $\left.\mathrm{HF}: \mathrm{H}_{2} \mathrm{O}_{2}: \mathrm{CH}_{3} \mathrm{COOH}: \mathrm{H}_{2} \mathrm{O}=1: 71: 75: 59\right)$ for 20 s, $60 \mathrm{~s}$, $100 \mathrm{~s}$, and $120 \mathrm{~s}$, followed by rinsing and drying of the nanowires. (B) The fraction of broken nanowires as a function of their diameter. The black curve represents an error function fit to the data. The critical diameter obtained from the fit is $19.2 \mathrm{~nm}$. Here, the diameters of 574 nanowires were measured. (C) Distribution of the length of all the broken nanowires at $t \geq 100 \mathrm{~s}$. The black curve is the Gaussian fit, from which we find the length of SiGe fragment to be $L=$ $120 \pm 18 \mathrm{~nm}$.

As the diameter of vertical nanowires shrink during the etching, they become fragile and prone to mechanical damage. ${ }^{43-45}$ The ability of the nanostructures to withstand various solution-based processes is essential for high-yield fabrication. Therefore, it is important to understand when and how the damage occurs during the entire etching process, which, in our case, consists of etching, two-step rinsing (i.e., rinsing in water followed by rinsing in isopropanol alcohol (IPA)), and drying under ambient conditions. Here, we found that the narrow SiGe nanowires (i.e., nanowires that were etched the longest) were mostly broken after the drying (Figure 3A: $t=120 \mathrm{~s}$ ). Figure $3 \mathrm{~B}-\mathrm{C}$ summarizes these results by showing the fraction of the broken nanowires as a function of their diameter. The critical diameter (i.e., diameter at which $50 \%$ of the nanowires are broken) is $\sim 19.2 \mathrm{~nm}$ (meaning that the critical aspect ratio for these nanowires is 8.2). From the images of the nanowires, it is clear that the $\mathrm{Si}$ base of the composite nanowire remained intact and attached to the $\mathrm{SiO}_{2}$ membrane at all times. The length of the broken nanowires found lying on the $\mathrm{SiO}_{2}$ membrane surface is $L=120 \pm 18 \mathrm{~nm}$ as opposed to their full length of $160 \mathrm{~nm}$, suggesting that the nanowires do not necessarily break at their SiGe/Si interface. Moreover, the dark contrast in the form of small circles within the larger Si base with lighter gray contrast corresponds to the 
remaining narrow SiGe fragment on the base (Figure 3A: $t=120 \mathrm{~s}$ ). Here, the damage was caused by post-etch drying where the capillary forces exerted by IPA broke the nanowires.
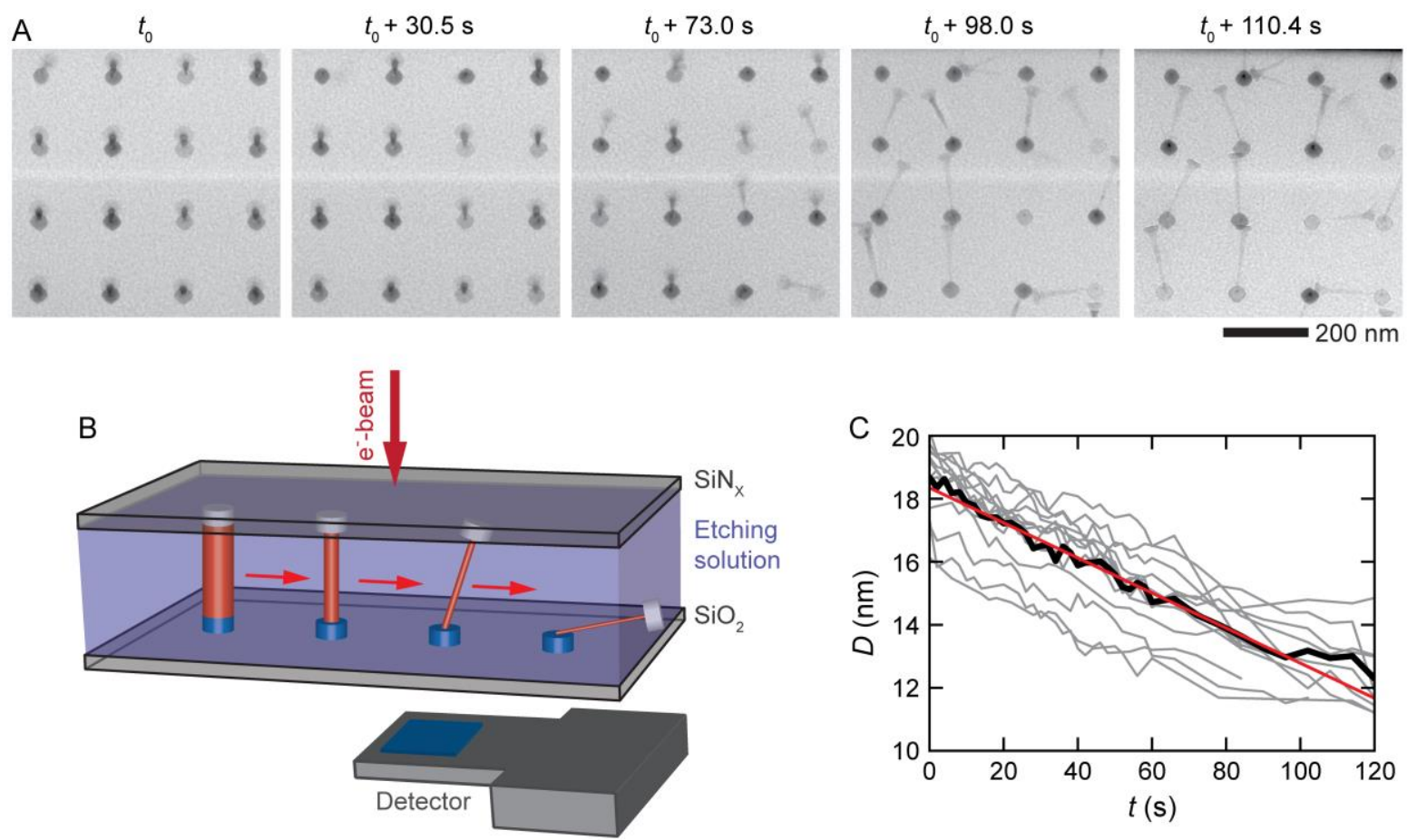

Figure 4. Visualizing the etching of SiGe with in situ liquid phase TEM. (A) In situ TEM image series showing the real-time etching of the nanowires in the solution-16 (HF: $\left.\mathrm{H}_{2} \mathrm{O}_{2}: \mathrm{CH}_{3} \mathrm{COOH}: \mathrm{H}_{2} \mathrm{O}=1: 200: 3: 0\right)$ (Supporting Video 1). (B) Schematic showing in situ liquid phase TEM imaging platform and the evolution of the nanowires during the etching. (C) Diameters of individual nanowires as a function of time are plotted in gray. The thick black curve represents the average of all the diameter curves. The red line is a weighted average of all individual linear fits. The etch rate of SiGe in this etching solution is $1.7 \pm 0.2 \mathrm{~nm} / \mathrm{min}$.

Next, to investigate if the nanowires break during the etching step and if so then how, we directly monitored the etching process in real-time using in situ liquid phase TEM imaging. ${ }^{46}$ Since capillary forces are only present during drying phase of the process, we expect the nanowires to remain intact in the solution during the etching even when their diameter is less than $19.2 \mathrm{~nm}$ (i.e., critical diameter for capillary damage). For in situ TEM etching observation, $1 \mu \mathrm{L}$ of solution-16 ( $\mathrm{HF}: \mathrm{H}_{2} \mathrm{O}_{2}: \mathrm{CH}_{3} \mathrm{COOH}: \mathrm{H}_{2} \mathrm{O}=1: 200: 3: 0$ ) was loaded into the pocket of a liquid cell, which was then sealed and inserted into TEM for imaging with low electron flux of $<10 \mathrm{e}^{-} /\left(\AA^{2} \cdot \mathrm{s}\right)$ at a rate of 10 frames per second (Figure 4A-B). ${ }^{46}$ Typically, there are a few minutes of delay between the loading of the solution into the liquid cell and the onset of imaging. Because of this delay, the nanowires were already partially etched once the imaging started (i.e., note that the nanowires are thinner at $t=t_{0}$ in Figure 4A compared to $t=0 \mathrm{~s}$ in Figure 3A). Here, all the nanowires were erect 
at the early stages of the etching $\left(t<t_{0}+30.5 \mathrm{~s}\right)$, albeit they appear slightly bent because of the curved $\mathrm{SiO}_{2}$ membrane due to bulging. ${ }^{47} \mathrm{At} t=t_{0}+73.0 \mathrm{~s}$, the nanowires start to bend significantly and eventually break when their diameters are $<15 \mathrm{~nm}$ in contrast to the post-etch drying critical diameter of $\sim 19.2 \mathrm{~nm}$ (Figure 3B). Again, note that the etching of Si bases is negligible because of selective SiGe etching (Figure 4A). As mentioned earlier, for this case, we can exclude the effect of the surface tension forces because here the nanowires are fully submerged inside the solution during the etching.

To identify how the nanowires break during the etching, we examined the fallen nanowires in the in situ movies and found the length of their fallen SiGe fragment to be $\sim 150 \mathrm{~nm}$. This length is very close to the original length of the SiGe fragment of the composite nanowire suggesting that nanowires are breaking at the SiGe/Si interface. Moreover, small circular dark contrast spots in the middle of the intact $\mathrm{Si}$ bases that are associated with the remnant SiGe fragments observed in ex situ studies (Figure 3A: $t=120 \mathrm{~s}$ ), are absent when the nanowires fall and break during the in situ etching studies (Figure 4A: $t=t_{0}+110.4 \mathrm{~s}$ ). Here it must be noted that similar to the ex situ etched nanowires (Figure 3A: $t=120 \mathrm{~s}$ ), the SiGe portion of the nanowires in Figure 4A appears tapered towards the $\mathrm{SiGe} / \mathrm{Si}$ interface, albeit slightly more pronounced here than in the ex situ case. Similar, tapering is also present in the original un-etched nanowires (Figure 1B). Therefore, it is possible that breaking at the interfaces could be due to the gradual shrinking and complete etching of the interface before the rest of the nanowire. However, we emphasize that strain at the interface does not result in faster interfacial etch rates ${ }^{48}$; hence we do not expect strain at $\mathrm{SiGe/Si}$ interface to induce faster local interfacial etch rates.

Another possible reason for nanowire breaking is the interfacial $(\mathrm{SiGe} / \mathrm{Si})$ stress. Note that the interfacial stress induced by a lattice mismatch between $\mathrm{Si}$ and $\mathrm{SiGe}$ is expected to be more significant for smaller nanostructures, ${ }^{49-50}$ and may cause the nanowires to break at the $\mathrm{SiGe} / \mathrm{Si}$ interface once the nanowire diameter is sufficiently small due to the etching. Recall that a significant fraction of thin nanowires also breaks during the drying phase, but they rarely break at $\mathrm{SiGe} / \mathrm{Si}$ interface (Figure 3A), which implies that structural integrity at the interface is compromised only when the nanowires are substantially thin. Therefore, nanowire breaking associated with interfacial stress at their $\mathrm{SiGe/Si}$ interface might eventually present a challenge for the fabrication of nanoscale high-aspect-ratio vertical heterostructures.

\section{Conclusions}

In conclusion, our results establish effective chemistries for selective wet etching of vertical SiGe nanostructures, which is based on the oxidation by $\mathrm{PAA} / \mathrm{H}_{2} \mathrm{O}_{2}$ and dissolution of the oxide by $\mathrm{HF}$. By systematically varying the concentration of the constituents in these etching solutions and measuring the corresponding etch rates of $\mathrm{SiGe}$ and $\mathrm{Si}$, we provide mechanistic insight into the 
etching process. Moreover, our observations show how nanowires break during the etching and identify the possible damage modes that are encountered during wet processes used in the fabrication of nanoscale structures. These insights are fundamental to improving current or devising new processes needed for the nanofabrication of next-generation microelectronics components. More broadly, our approach to observing critical processes relevant to semiconductor fabrication provides a valuable metrology platform for process development.

\section{Experimental Section}

Materials: Etching solutions were prepared from the following stock solutions: $\mathrm{H}_{2} \mathrm{O}_{2}(30 \%$, Dickson Chemical, Singapore), $\mathrm{CH}_{3} \mathrm{COOH}$ (100\%, Cat. No. VWRC20104.323, VWR International LLC, Radnor, PA, USA), and HF (48\%, Cat. No. 695068-500 mL, Sigma-Aldrich Co. LLC, St. Louis, MO, USA), and de-ionized water $\left(\mathrm{H}_{2} \mathrm{O}\right)$. The details of all the etching solutions used in our study are presented in the Supporting Section 1.

Fabrication of devices: The device chips with composite $\mathrm{SiN}_{\mathrm{x}} / \mathrm{Si}_{0.75} \mathrm{Ge}_{0.25} / \mathrm{Si}$ nanowires on top of a $\mathrm{SiO}_{2}$ membrane were fabricated from a 300-mm SOI (Silicon-on-Insulator) wafer with an 88nm-thick c-Si layer on top of a 145-nm-thick buried oxide (BOX) layer. First, the c-Si layer was thinned down to $\sim 30 \mathrm{~nm}$ by partial oxidation of the Si layer, followed by etching the oxidized $\mathrm{Si}$ layer in HF. After the thinning, we deposited a 160 -nm-thick epitaxial layer of c-Si ${ }_{0.75} \mathrm{Ge}_{0.25}$. Then, a 30-nm-thick LPCVD amorphous $\mathrm{SiN}_{\mathrm{x}}$ film was deposited on both sides of the wafer, followed by deposition of a multilayer hardmask on top of the front-side $\mathrm{SiN}_{\mathrm{x}}$ film. Next, using deep ultraviolet (DUV) immersion lithography, we printed 90-nm pitch nanodots in photoresist through double line exposures. ${ }^{51-52}$ The resist pattern was then transferred into the underlying hardmask for the subsequent multistep plasma etching of the $\mathrm{SiN}_{\mathrm{x}} / \mathrm{Si}_{0.75} \mathrm{Ge}_{0.25} / \mathrm{Si}$ multilayer. A soft-landing step with high selectivity of $\mathrm{Si}$ over $\mathrm{SiO}_{2}$ was used to ensure straight nanowire profiles and to avoid any underetching of the nanowires at the $\mathrm{SiO}_{2} / \mathrm{Si}$ interface. The height of the patterned nanowires was defined by the thickness of the $\mathrm{SiN}_{\mathrm{x}} / \mathrm{Si}_{0.75} \mathrm{Ge}_{0.25} / \mathrm{Si}$ stack, which was approximately $220 \mathrm{~nm}$ (Figure 1D). After the fabrication nanowires had slight tapering; their diameter at $\mathrm{SiN}_{\mathrm{x}} / \mathrm{Si}$ and $\mathrm{SiGe} / \mathrm{Si}$ interfaces were $51 \pm 2 \mathrm{~nm}$ and $48 \pm 2 \mathrm{~nm}$, respectively.

After the nanowire fabrication process, backside etching was performed to define individual chips and remove the bulk $\mathrm{Si}$ and release the free-standing $\mathrm{SiO}_{2}(\mathrm{BOX})$ membrane with the vertical composite nanowires (Figure 1A-C). This last step of fabrication and the assembly of the liquid cells for in situ liquid phase TEM imaging are described in more detail in the supporting information of our earlier work. ${ }^{46}$ 
Imaging: TEM images both for ex situ and in situ etching experiments were acquired with a JEOL 2010FEG TEM (JEOL Ltd. Akishima, Tokyo, Japan) operated at $200 \mathrm{kV}$ and equipped with a OneView CMOS camera (Gatan, Inc., Pleasanton, CA, USA). For in situ liquid phase TEM studies, we used our custom-built TEM holder designed for static liquid cells. ${ }^{46}$ In situ TEM images were recorded at a rate of 10 frames per second with the electron flux of $<10 \mathrm{e}^{-} /\left(\AA^{2} \cdot \mathrm{s}\right)$. Details of the image analysis used for this work are described in the Supporting Information Section 2.

\section{Associated Content}

The supporting information is available free of charge on ACS Publications website.

Supplementary text and figures discussing the details of etching solutions and image analysis. (PDF)

Supporting Video: In situ TEM movie showing the selective etching of SiGe of thin composite nanowires in the etching solution-16 (HF:H2O2:CH3COOH:H2O = 1:200:3:0). (AVI)

\section{Acknowledgment}

This work was supported by the Singapore National Research Foundation's Competitive Research Program funding (NRF-CRP16-2015-05).

\section{References}

(1) Waldrop, M. M. The Chips Are Down for Moore's Law. Nature 2016, 530, 144-147.

(2) Kuhn, K. J. Considerations for Ultimate CMOS Scaling. IEEE Trans. Electron Devices 2012, 59, 1813-1828.

(3) Mertens, H.; Ritzenthaler, R.; Hikavyy, A.; Kim, M.-S.; Tao, Z.; Wostyn, K.; Chew, S. A.; De Keersgieter, A.; Mannaert, G.; Rosseel, E. In Gate-All-around Mosfets Based on Vertically Stacked Horizontal Si Nanowires in a Replacement Metal Gate Process on Bulk Si Substrates, VLSI Technology, 2016 IEEE Symposium on, IEEE: 2016; pp 1-2.

(4) Veloso, A.; Huynh-Bao, T.; Rosseel, E.; Paraschiv, V.; Devriendt, K.; Vecchio, E.; Delvaux, C.; Chan, B.; Ercken, M.; Tao, Z. In Challenges and Opportunities of Vertical FET Devices Using 3D Circuit Design Layouts, 2016 IEEE SOI-3D-Subthreshold Microelectronics Technology Unified Conference (S3S), IEEE: 2016; pp 13.

(5) Yakimets, D.; Eneman, G.; Schuddinck, P.; Bao, T. H.; Bardon, M. G.; Raghavan, P.; Veloso, A.; Collaert, N.; Mercha, A.; Verkest, D. Vertical GAAFETs for the Ultimate CMOS Scaling. IEEE Trans. Electron Devices 2015, 62, 1433-1439.

(6) Brunner, K. Si/Ge Nanostructures. Reports on Progress in Physics 2001, 65, 27-72.

(7) Choi, Y.-K.; Lindert, N.; Xuan, P.; Tang, S.; Ha, D.; Anderson, E.; King, T.-J.; Bokor, J.; Hu, C. In Sub-20 Nm CMOS FinFET Technologies, Electron Devices Meeting, 2001. IEDM'01. Technical Digest. International, IEEE: 2001; pp 19.1. 1-19.1. 4. 
(8) Ghani, T.; Armstrong, M.; Auth, C.; Bost, M.; Charvat, P.; Glass, G.; Hoffmann, T.; Johnson, K.; Kenyon, C.; Klaus, J. In A 90nm High Volume Manufacturing Logic Technology Featuring Novel 45nm Gate Length Strained Silicon CMOS Transistors, Electron Devices Meeting, 2003. IEDM'03 Technical Digest. IEEE International, IEEE: 2003; pp 11.6. 1-11.6. 3.

(9) Sun, Y.; Thompson, S.; Nishida, T. Physics of Strain Effects in Semiconductors and Metal-OxideSemiconductor Field-Effect Transistors. J. Appl. Phys. 2007, 101, 104503.

(10) Rim, K.; Welser, J.; Hoyt, J.; Gibbons, J. In Enhanced Hole Mobilities in Surface-Channel Strained-Si PMOSFETs, Electron Devices Meeting, 1995. IEDM'95., International, IEEE: 1995; pp 517-520.

(11) Lee, M. L.; Fitzgerald, E. A.; Bulsara, M. T.; Currie, M. T.; Lochtefeld, A. Strained Si, SiGe, and Ge Channels for High-Mobility Metal-Oxide-Semiconductor Field-Effect Transistors. J. Appl. Phys. 2005, 97, 1. (12) Veloso, A.; Altamirano-Sánchez, E.; Brus, S.; Chan, B.; Cupak, M.; Dehan, M.; Delvaux, C.; Devriendt, K.; Eneman, G.; Ercken, M. Vertical Nanowire FET Integration and Device Aspects. ECS Trans. 2016, 72, 3142.

(13) Jin, S.; Fischetti, M. V.; Tang, T.-w. Modeling of Electron Mobility in Gated Silicon Nanowires at Room Temperature: Surface Roughness Scattering, Dielectric Screening, and Band Nonparabolicity. J. Appl. Phys. 2007, 102, 083715.

(14) Thean, A. V.; Yakimets, D.; Bao, T. H.; Schuddinck, P.; Sakhare, S.; Bardon, M. G.; Sibaja-Hernandez, A.; Ciofi, I.; Eneman, G.; Veloso, A. In Vertical Device Architecture for 5nm and Beyond: Device \& Circuit Implications, 2015 Symposium on VLSI Technology (VLSI Technology), IEEE: 2015; pp T26-T27.

(15) Guerfi, Y.; Larrieu, G. J. N. r. I. Vertical Silicon Nanowire Field Effect Transistors with Nanoscale GateAll-Around. Nanoscale Res. Lett. 2016, 11, 210.

(16) Shul, R. J.; Pearton, S. J. Handbook of Advanced Plasma Processing Techniques, Springer Science \& Business Media: 2011.

(17) Richard, O.; lacopi, F.; Bender, H.; Beyer, G. Sidewall Damage in Silica-Based Low-K Material Induced by Different Patterning Plasma Processes Studied by Energy Filtered and Analytical Scanning Tem. Microelectron. Eng. 2007, 84, 517-523.

(18) Taylor, H. K.; Sun, H.; Hill, T. F.; Farahanchi, A.; Boning, D. S. Characterizing and Predicting Spatial Nonuniformity in the Deep Reactive Ion Etching of Silicon. J. Electrochem. Soc. 2006, 153, C575-C585.

(19) Wu, B.; Kumar, A.; Pamarthy, S. High Aspect Ratio Silicon Etch: A Review. J. Appl. Phys. 2010, 108, 9.

(20) Zhang, Y.; Oehrlein, G. S.; de Frésart, E.; Corbett, J. W. Reactive lon Etching of SiGe Alloys Using Cf2Cl2. J. Appl. Phys. 1992, 71, 1936-1942.

(21) Caubet, V.; Beylier, C.; Borel, S.; Renault, O. Mechanisms of Isotropic and Selective Etching between SiGe and Si. J. Vac. Sci. Technol. B 2006, 24, 2748-2754.

(22) Oehrlein, G.; Kroesen, G.; De Frésart, E.; Zhang, Y.; Bestwick, T. Studies of the Reactive lon Etching of SiGe Alloys. J. Vac. Sci. Technol. A 1991, 9, 768-774.

(23) Zhuang, D.; Edgar, J. Wet Etching of GaN, AIN, and SiC: A Review. Mater. Sci. Eng. R Rep. 2005, 48, 146.

(24) Krist, A.; Godbey, D.; Green, N. Selective Removal of a $\mathrm{Si}_{0.7} \mathrm{Ge}_{0.3}$ Layer from Si (100). Appl. Phys. Lett. 1991, 58, 1899-1901.

(25) Godbey, D.; Krist, A.; Hobart, K.; Twigg, M. Selective Removal of $\mathrm{Si}_{1-x} \mathrm{Ge}_{\mathrm{x}}$ from (100) $\mathrm{Si}$ Using $\mathrm{HNO}_{3}$ and Hf. J. Electrochem. Soc. 1992, 139, 2943-2947.

(26) Schwartz, B.; Robbins, $\mathrm{H}$. Chemical Etching of Germanium in Solutions of $\mathrm{HF}, \mathrm{HNO}_{3}, \mathrm{H}_{2} \mathrm{O}$, and $\mathrm{HC}_{2} \mathrm{H}_{3} \mathrm{O}_{2}$. J. Electrochem. Soc. 1964, 111, 196-201.

(27) Bloem, J.; Van Vessem, J. Etching Ge with Mixtures of $\mathrm{HF}-\mathrm{H}_{2} \mathrm{O}_{2}-\mathrm{H}_{2}$ O. J. Electrochem. Soc. 1962, 109, 33-36.

(28) Robbins, H.; Schwartz, B. Chemical Etching of Silicon li. The System, And. J. Electrochem. Soc. 1960, 107, 108-111. 
(29) Chang, G.; Carns, T.; Rhee, S.; Wang, K. Selective Etching of SiGe on SiGe/Si Heterostructures. J. Electrochem. Soc. 1991, 138, 202-204.

(30) Luukkonen, T.; Pehkonen, S. O. Peracids in Water Treatment: A Critical Review. Crit. Rev. Environ. Sci. Technol. 2017, 47, 1-39.

(31) Zhao, X.; Zhang, T.; Zhou, Y.; Liu, D. Preparation of Peracetic Acid from Hydrogen Peroxide: Part I: Kinetics for Peracetic Acid Synthesis and Hydrolysis. J. Mol. Catal. A: Chem. 2007, 271, 246-252.

(32) Parker, W. E.; Ricciuti, C.; Ogg, C.; Swern, D. Peroxides. li. Preparation, Characterization and Polarographic Behavior of Longchain Aliphatic Peracids2. J. Am. Chem. Soc. 1955, 77, 4037-4041.

(33) Knotter, D. M. Etching Mechanism of Vitreous Silicon Dioxide in HF-Based Solutions. J. Am. Chem. Soc. 2000, 122, 4345-4351.

(34) Deegan, T.; Hughes, G. An X-Ray Photoelectron Spectroscopy Study of the HF Etching of Native Oxides on Ge (111) and Ge (100) Surfaces. Appl. Surf. Sci. 1998, 123, 66-70.

(35) Holländer, B.; Buca, D.; Mantl, S.; Hartmann, J. Wet Chemical Etching of $\mathrm{Si}_{1} \mathrm{Si}_{1-} \mathrm{Ge}_{x}$, and Ge in $\mathrm{Hf}: \mathrm{H}_{2} \mathrm{O}_{2}: \mathrm{CH}_{3} \mathrm{COOH}$. J. Electrochem. Soc. 2010, 157, H643-H646.

(36) Cams, T.; Tanner, M.; Wang, K. Chemical Etching of $\mathrm{Si}_{1-x} \mathrm{Ge}_{x}$ in $\mathrm{HF}: \mathrm{H}_{2} \mathrm{O}_{2}: \mathrm{CH}_{3} \mathrm{COOH}$. J. Electrochem. Soc. 1995, 142, 1260-1266.

(37) Taraschi, G.; Pitera, A. J.; Fitzgerald, E. A. Strained Si, SiGe, and Ge on-Insulator: Review of Wafer Bonding Fabrication Techniques. Solid.State Electron. 2004, 48, 1297-1305.

(38) Guder, M.; Kolbesen, B. O.; Delattre, C.; Fischer, C.; Schier, H.; Wagner, G. In Peracetic Acid as Active Species in Mixtures for Selective Etching of SiGe/Si Layer Systems-Aspects of Chemistry and Analytics, Solid State Phenom., Trans Tech Publ: 2008; pp 79-82.

(39) Salvetat, T.; Destefanis, V.; Borel, S.; Hartmann, J.-M.; Kermarrec, O.; Campidelli, Y. Comparison between Three $\mathrm{Si}_{1-x} \mathrm{Ge}_{\mathrm{x}}$ Versus Si Selective Etching Processes. ECS Trans. 2008, 16, 439-449.

(40) Zhao, X.-b.; Zhang, T.; Zhou, Y.-j.; Liu, D.-h. Preparation of Peracetic Acid from Acetic Acid and Hydrogen Peroxide: Experimentation and Modeling. Chin. J. Process Eng. 2008, 8, 35-41.

(41) Dul'neva, L.; Moskvin, A. Kinetics of Formation of Peroxyacetic Acid. Russ. J. Gen. Chem. 2005, 75, 1125-1130.

(42) Janković, M.; Sinadinović - Fišer, S. Prediction of the Chemical Equilibrium Constant for Peracetic Acid Formation by Hydrogen Peroxide. J. Am. Oil Chem.' Soc. 2005, 82, 301-303.

(43) Chang, C.-C.; Wang, Z.; Sheng, Y.-J.; Tsao, H.-K. Nanostructure Collapse by Elasto-Capillary Instability. Soft Matter 2014, 10, 8542-8547.

(44) Hattori, T. Non-Aqueous Cleaning Challenges for Preventing Damage to Fragile Nano-Structures: A Review. ECS J. Solid State Sci. Technol. 2014, 3, N3054-N3059.

(45) Zeniou, A.; Ellinas, K.; Olziersky, A.; Gogolides, E. Ultra-High Aspect Ratio Si Nanowires Fabricated with Plasma Etching: Plasma Processing, Mechanical Stability Analysis against Adhesion and Capillary Forces and Oleophobicity. Nanotechnology 2013, 25, 035302.

(46) Aabdin, Z.; Xu, X. M.; Sen, S.; Anand, U.; Král, P.; Holsteyns, F.; Mirsaidov, U. Transient Clustering of Reaction Intermediates During Wet Etching of Silicon Nanostructures. Nano Lett. 2017, 17, 2953-2958.

(47) De Jonge, N.; Ross, F. M. Electron Microscopy of Specimens in Liquid. Nat. Nanotechnol. 2011, 6, 695704.

(48) Stoffel, M.; Malachias, A.; Merdzhanova, T.; Cavallo, F.; Isella, G.; Chrastina, D.; Von Känel, H.; Rastelli, A.; Schmidt, O. SiGe Wet Chemical Etchants with High Compositional Selectivity and Low Strain Sensitivity. Semicond. Sci. Technol. 2008, 23, 085021.

(49) Kim, T. G.; Pacco, A.; Wostyn, K.; Brems, S.; Xu, X. M.; Struyf, H.; Arstila, K.; Vandevelde, B.; Park, J. G.; De Gendt, S. In Effects of Interfacial Strength and Dimension of Structures on Physical Cleaning Window, Solid State Phenom., Trans Tech Publ: 2012; pp 123-126.

(50) Montalenti, F.; Rovaris, F.; Bergamaschini, R.; Miglio, L.; Salvalaglio, M.; Isella, G.; Isa, F.; von Känel, H. J. C. Dislocation-Free SiGe/Si Heterostructures. Crystals 2018, 8, 257. 
(51) Li, J.; Chen, C.; Jans, H.; Xu, X.; Verellen, N.; Vos, I.; Okumura, Y.; Moshchalkov, V. V.; Lagae, L.; Van Dorpe, P. 300 mm Wafer-Level, Ultra-Dense Arrays of Au-Capped Nanopillars with Sub-10 nm Gaps as Reliable SERS Substrates. Nanoscale 2014, 6, 12391-12396.

(52) Vos, I.; Hellin, D.; Vertommen, J.; Demand, M.; Boullart, W. Silicon Nano-Pillar Test Structures for Quantitative Evaluation of Wafer Drying Induced Pattern Collapse. ECS Trans. 2011, 41, 189-196. 